
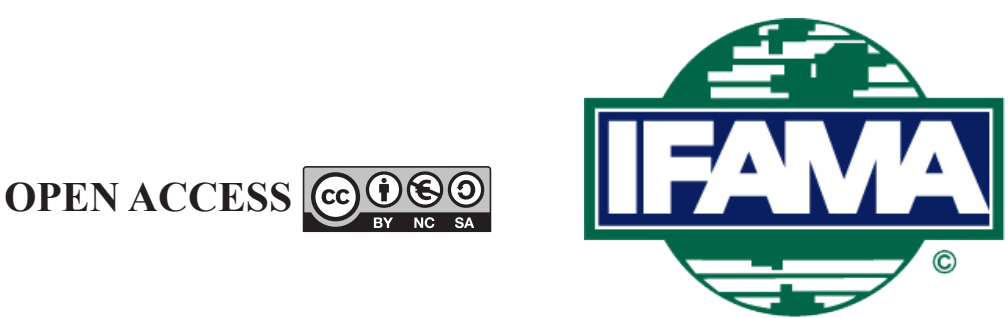

International Food and Agribusiness Management Review

Volume 24, Issue 6, 2021; DOI: 10.22434/IFAMR2020.0158

Received: 11 September 2020 / Accepted: 25 February 2021

Special Issue: IFAMA 2020 symposium

\title{
Effects of pollinator related information on consumer preference for neonicotinoid labeling
}

\section{RESEARCH ARTICLE}

\author{
Hayk Khachatryan ${ }^{\circledR a}$, Xuan Wei ${ }^{\mathrm{b}}$ and Alicia Rihn ${ }^{\mathrm{c}}$ \\ ${ }^{a}$ Associate Professor, ${ }^{b}$ Postdoctoral Research Associate, Food and Resource Economics Department and \\ Mid-Florida Research and Education Center, University of Florida, 2725 S. Binion Rd, Apopka, FL 32703-8504, USA \\ ${ }^{c}$ Assistant Professor, Department of Agricultural and Resource Economics, \\ University of Tennessee-Knoxville, 321C Morgan Hall, 2621 Morgan Circle, Knoxville, TN 37996, USA
}

\begin{abstract}
Despite increasing concerns about the potential negative impacts of neonicotinoid insecticides on pollinator insect health in the regulatory community, public perceptions about the use of such pest management tools are mainly unknown. To assess U.S. consumers' feedback to information linking neonicotinoid insecticides to pollinator health, the present study investigated consumers' preferences for different neonicotinoid labels. Specifically, it analyzed the effect of negative and balanced pollinator related information treatments on consumers' preferences for labels disclosing the absence or presence of neonicotinoids. The effects of the information treatments were asymmetric, with the negative information treatment having a more substantial impact on individual choices. Information treatments were more effective at influencing participants' willingness to pay (WTP) for labels disclosing the absence of neonicotinoids, as opposed to labels disclosing the presence of neonicotinoids. Preexisting knowledge about neonicotinoid insecticides had a significant impact on how individuals responded to information treatments.
\end{abstract}

Keywords: stated choice experiment, information treatment, neonicotinoid labeling, ornamental plants JEL code: D12, Q18, Q50, C90

\footnotetext{
(i)Corresponding author: hayk@ufl.edu
} 


\section{Introduction}

The ultimate goal of labeling is to provide information for consumers to make informed choices. While food labeling addresses concerns to public health, labeling neonicotinoid insecticides addresses the potential risks to pollinators' health and environmental sustainability. Whether labeling food or neonicotinoids, the function of disclosing information does not change. The controversial aspects of food labeling (Messer et al., 2017) thus also apply to neonicotinoid labeling practices. Investigating the relationship between consumers' knowledge and acceptance of pesticide labeling is important because the debate of neonicotinoid insecticide use and policy interventions in the U.S. should ideally involve an informed public.

Numerous studies have found that providing information about the public benefits of a good will effectively increase consumers' valuations of the good (e.g. Bougherara and Combirs, 2009; Li and McCluskey, 2017; Li et al., 2019; Lusk et al., 2004; Messer et al., 2017; Rousseau and Vranken, 2013). Any policy interventions (e.g. a ban or mandatory labeling) are presumably drawn upon extensive discussions by policy makers, green (horticultural) industry stakeholders, and the 'interested and informed public.' Nonetheless, the national level of public knowledge about neonicotinoids is minimal. According to previous studies, less than $20 \%$ of U.S. consumers have even heard about the term neonicotinoids (Rihn and Khachatryan, 2016; Wollaeger et al., 2015). Additionally, labeling format has the potential to influence the effectiveness of the information. For example, using a compensating variation to measure consumer welfare, Hu et al. (2005) found that information in the context of mandatory labeling was more valuable than voluntary labeling. Liaukonyte $e t$ al. (2013) found that the positive impact of labels communicating attribute absence (Free of X) on willingness to pay (WTP) only exists when secondary information is provided. Streletskaya et al. (2019) demonstrated that WTP for absence labels (e.g. organic labels) was affected not only by the label certification standards for organic labels, but also by the information about conventional production practices. Particularly, the most recent study by Campbell and Steele (2020) investigated the effects of both information source and information type on consumers' decisions to purchase pollinator-friendly plants. They found consumers exposed to either negative or neutral information from universities and major media outlets are more likely to purchase pollinator-friendly plants. In this study, we incorporate two (negative and balanced) information treatments to examine how consumers react to additional information and to test how this information may affect the effectiveness of different messages communicating the presence or absence of neonicotinoids. The structure of our information treatments is similar to Campbell and Steele (2020). While Campbell and Steele (2020) provided statements regarding whether there is a link/no link between pesticides and pollinator decline (negative/neutral information treatment) and varying information statements by different source type (e.g. environmental group, government, industry), we incorporated multiple sources of information (scientific research results, news broadcasting) with the negative and balanced information videos.

In response to discussion among industry and regulatory stakeholders related to genetic modification (GM) technology in the agronomic and food industries, numerous studies investigated the effects of mandatory versus voluntary labeling, consumer perceptions, and acceptance of GM foods (e.g. Cook et al., 2006; Frewer et al., 2002; Hu, 2006; Lusk et al., 2004; McFadden and Lusk, 2018; Vilella-Vila and Costa-Font, 2008). Previous studies reported that consumer acceptance of and WTP for GM foods is lower than non-GM foods (McFadden and Lusk, 2018), often due to increased perceptions of risk to personal health and the environment (Frewer et al., 2002). Press coverage has been shown to influence public perceptions and cause a media bias (Vilella-Vila and Costa-Font, 2008). Cook et al. (2006) demonstrated that negative perceptions, which are frequently promoted by anti-GM groups, often override the pro-GM science-based press. Similarly, Frewer et al. (2002) demonstrated that negative information about GM permanently depresses consumer acceptance of the potential benefits of the technology. Drawing insights from food labeling literature, we aim to verify the parallel existence of consumer acceptance when applied to labeling pesticides on ornamental plants. The primary purpose of this study is to investigate the effects of information on consumers' preferences for products that contain or are free of neonicotinoid pesticides labeled in different graphic and text formats. Specifically, the first objective is to investigate the effects of additional neonicotinoid pesticide and pollinator health information on consumers' purchasing decisions. Second, we examine whether additional information 
treatments may have differentiated impacts on consumers' preferences for labeling content (i.e. disclosing the absence or the presence of neonicotinoids). The third objective is to investigate whether consumers with different preexisting knowledge about neonicotinoids and pollinators react differently to additional information.

\subsection{Background on neonicotinoid insecticides}

Neonicotinoids are the most widely used class of insecticides in agricultural production (Goulson, 2013; Jeschke et al., 2011) with registered applications in more than 120 countries and seed coatings accounting for $60 \%$ of all neonicotinoids used (Jeschke et al., 2011). Between 2003 and 2011, neonicotinoid applications in the U.S. increased dramatically with maize, cotton, and soybeans, accounting for $80 \%$ of all neonicotinoids used (Douglas and Tooker, 2015). Additionally, the volume of neonicotinoid insecticides applied to corn doubled between 2011 and 2014 due to increased seed coating application rates (Tooker et al., 2017).

In the early 2000s, the planting of neonicotinoid-treated corn seeds coincided with mass bee deaths in several European Union (EU) countries leading to speculations that it may have contributed to pollinator declines. Since then, interest among public and private firms in determining whether neonicotinoids cause declines of managed and wild bee populations has escalated (Goulson, 2013; Van de Sluijs et al., 2013). Existing studies provide mixed conclusions, and the controversy between the use of neonicotinoid insecticides and issues related to pollinator health remain unresolved. Some studies suggested that neonicotinoids negatively implicate bee health (Goulson et al., 2015; Pisa et al., 2015; Sanchez-Bayo and Goka, 2014; Van de Sluijs et al., 2013), while other research found that neonicotinoids do not significantly impact bees (Fairbrother et al., 2014; Pilling et al., 2013). More recent studies discovered that neonicotinoid seed treatments negatively impact natural-enemy insect populations (Douglas and Tooker, 2016) and crop physiology and defenses (Tooker et al., 2017). Review articles have found considerable variations between laboratory experiments and field trials, thus question inferences and implications of the results (e.g. Blacquiere et al., 2012; Lundin et al., 2015).

Despite scientific uncertainty, concerns for pollinators have led EU regulators to impose a temporary ban on three neonicotinoids (clothianidin, thiamethoxamand, and imidacloprid) in December 2013. After the EU ban, Noleppa's (2017) review of 13 studies revealed that the neonicotinoid ban caused an average of $4.0 \%$ yield decrease in EU oilseed rape production and an annual increase of production costs by at least 117.5 million Euro solely due to the costs of additional foliar insecticide application and associated application/labor costs. The consequences of the ban may be more severe for small-size operations that cannot afford extra expenditures within integrated pest management programs. Even though active ingredients in neonicotinoids were predominantly sold in crop-use products (93\%), the remainder were mostly absorbed in the ornamental industry: 4\% sold in turf/ornamental and 1.2\% in lawn/garden (Douglas and Tooker, 2015). The use of pesticides to maintain plant quality represents a significant strategy for ornamental producers to stay competitive. Neonicotinoids are among the most effective insecticides for control of insect pests such as aphids and whiteflies in ornamental plant production (Jeschke and Nauen, 2008; Jeschke et al., 2011). Compared to ornamental crops, agricultural crops (row crops) have less economic value per plant and can tolerate a certain level of damage from arthropod pests without compromising yields and salability. Pest control in ornamental production is more challenging owing to the diversity of crops grown, intensive nature of production, desired aesthetic appearance and the consumer demand for high-quality plants that are free of damage (Bethke and Cloyd, 2009). In contrast to the EU, U.S. regulators took a more cautious step toward restricting the use of neonicotinoids. In 2013, the U.S. Environmental Protect Agency (EPA) launched new labeling policies for neonicotinoid insecticides, which added a warning about honeybees and other pollinators to the labels. While policy intervention is still under investigation by the U.S. federal government, several sizable retail garden supply stores announced mandatory labeling policies for plants treated with neonicotinoid insecticides. This action has generated a large amount of media attention and research interest. For instance, studies analyzing consumer preferences for pollinator-friendly products (e.g. Campbell and Steele, 2020; Rihn and Khachatryan, 2016; Wei et al., 2020; Wollaeger et al., 2015) are growing in the eco-labeling and production practice related literature (Bougherara and Combris, 2009; Meise et al., 2014; Michaud et al., 
2013; Sörqvist et al., 2015; Van Loo et al., 2015). However, none of the previous efforts investigated whether providing issue-specific information (i.e. the potential risks neonicotinoids pose to pollinator health) would impact on consumer preferences for products treated with or without neonicotinoid insecticides.

\section{Materials and methods}

\subsection{Survey and experimental design}

Consumers' preferences for eco-labeling can be elicited using the contingent valuation, a choice-based conjoint analysis, or an experiment auction (Lusk and Hudson, 2014). A choice-based internet survey incorporating information treatments was deemed as an acceptable data collection method for this study for the following reasons. First, given low general public knowledge about neonicotinoids, an online survey provides an efficient mechanism to reach a representative sample. Secondly, an online survey allows to incorporate information treatment videos into the survey and randomly assign survey participants to different treatment groups (Dillman et al., 2011; Griffis et al., 2003). An online choice experiment may be undermined by its hypothetical nature, stated preference nonetheless can provide insights into how consumers respond to various treatments. Several attention check questions were included to detect participants who did not thoroughly read the survey questions.

Following Kuhfeld (2010), a fractional factorial orthogonal design was employed in this choice experiment using software JMP Pro 11 (SAS Institute Inc., Vary, NC, USA). Three popular annual bedding plants (Impatiens, Marigold, and Pentas) and three popular perennial plants (Dianthus, Chrysanthemum, and Salvia) were selected based on annual sales values reported by USDA NASS (2014). ${ }^{1}$ The main attributes used in the experiment are listed in Supplementary Table S1. Four neonicotinoid insecticide related labeling attributes included 'neonicotinoid free' (text), 'bee better certified' (logo), 'treated with neonicotinoids' and 'protected from problematic pests by neonicotinoids'. Container type was indicated by either 'conventional plastic' or 'bio-degradable'. Further, four price levels were considered in the choice experiment $(\$ 1.15, \$ 1.65$, $\$ 2.49$ and $\$ 3.99$ for annual bedding plants; $\$ 5.99, \$ 6.99, \$ 8.49$ and $\$ 10.49$ for perennial plants). These price levels were selected based on local retail outlet prices (i.e. big box garden stores and independent garden centers). Two blocks of 16 choice scenarios were constructed separately for annual bedding plants (with a D-efficiency of 95.04\%) and perennial plants (with a D-efficiency of 95.54\%) with each block consisting of eight choice scenarios. Each respondent was randomly assigned to view one block of eight annual bedding plants and one block of eight perennial plants. With a randomized order of blocks, survey respondents made a total of 16 choices. By doing so, we ensured the variation observed in the choices was attributable to the variation in attributes and attribute levels that we were interested in, but not due to possible preferences to specific crop or plant types.

Participants were screened to ensure they lived in a home with a yard and had purchased plants within the past 12 months. At the beginning of the internet survey, participants answered questions regarding their knowledge about pollinators and pollinator attractive plants, knowledge about neonicotinoid insecticides, as well as perceptions on labeling practices. Survey respondents were then randomly directed to one of the information treatments (i.e. control, negative, or balanced information treatments). For the control group, no additional information was provided. Respondents completed the choice experiment based on their existing knowledge and beliefs about pollinators and neonicotinoids. Meanwhile, respondents in the two information treatment groups made 16 choices after viewing a three-minute informational video, depending on which treatment they received. Participants were instructed to imagine a real situation of purchasing a plant before the choice experiment, even though they were not bound to buy one of the products.

\footnotetext{
${ }^{1}$ According to 2014 NASS survey results, the sales values of Impatiens (other), Marigold and Pentas were ranked the $5^{\text {th }}, 7^{\text {th }}$ and $25^{\text {th }}$ of all annual bedding plants while the sales values of Chrysanthemum, Salvia and Dianthus were ranked the $1^{\text {st }}, 5^{\text {th }}$, and $6^{\text {th }}$ of all perennial plants.
} 
During the choice experiment, survey respondents viewed pictures of annual bedding and perennial plants. They were informed that the annual bedding plants were in 4-inch containers, and the perennial plants were in 1-gallon containers to accurately reflect the actual products available in retail outlets. In each choice scenario (Supplementary Figure S1), survey respondents selected the product they preferred from one of three options: plant A, plant B, or an opt-out option (i.e. I would not buy any of these plants). The online survey concluded with respondents' shopping behaviors and demographic information questions.

\subsection{Labeling practice related attributes}

Two types of eco-labels were employed in this study. The first type of label, which is the main focus of the present study, communicated the absence or presence of neonicotinoids. The second eco-label included in the choice experiment described container type (biodegradable vs conventional). While the disclosure of container type is typically voluntary in the ornamental plants industry, the disclosure of the absence or presence of neonicotinoids could be either mandatory or voluntary, similar to GM labeling in food (McFadden and Lusk, 2018). In a mandatory labeling practice, all plants grown using neonicotinoids are required to clearly indicate the use of such insecticides. Conversely, a voluntary labeling scheme gives producers the flexibility to choose the information included on the label (Caswell, 2000). In a voluntary labeling practice, producers and suppliers have no incentives to label their products unless a specific attribute is expected to appeal to consumers, resulting in increased sales and profits (Hu et al., 2005). In the case of neonicotinoid labeling, statements such as 'neonicotinoids free' on a plant label are attempts to indicate environmental benefits due to the potential risks of neonicotinoids to pollinators.

Four types of neonicotinoid labeling contents were considered in the choice experiment as follows. 'Treated with neonicotinoids' and 'protected from problematic pests by neonicotinoids' (phrasing currently used by a major gardening supplies retailer) were used to communicate the presence of neonicotinoids, representing a mandatory labeling scenario. Meanwhile, 'neonicotinoid free' (text) and 'Bee Better Certified ${ }^{\mathrm{TM}}$ ' (logo) were used to communicate the absence of neonicotinoids, representing voluntary labeling practices. 'Neonicotinoid free' (text) is spontaneously used by some producers and suppliers in the ornamental horticulture industry to promote pollinator conservation efforts. Meanwhile, the 'Bee Better Certified ${ }^{\mathrm{TM}}$ ' products and ingredient seals are certified to be used on products that contain a majority of ingredients sourced from 'bee better certified' farms or contain one or more certified ingredients. Considering that the presence or absence of neonicotinoids are mutually exclusive, we did not include a 'no label' option as one of the attribute levels. Further, information regarding containers (biodegradable vs conventional) was displayed as an additional measure of sustainable production practices.

\subsection{Information treatments}

The experiment employed between-subject treatments to test whether negative and balanced information affects participants' preferences toward labels disclosing the presence or absence of neonicotinoids. The effectiveness of the two information treatments was compared with the status quo baseline.

\section{- Negative information}

While providing information about a good's public component effectively increases consumers' valuations of the good, the nature of the information and how it is framed matters a lot (McCluskey et al., 2016). Recognizing the positive-negative asymmetry in human behaviors (Baumeister et al., 2001; Peeters and Czapinski, 1990), numerous studies confirm that negative information has a stronger impact on consumer behavior than positive information (Fox et al., 2002; McCluskey and Swinnen, 2004; Siegrist and Cvetkovich, 2001; Weinberger and Dillon, 1980). Here, participants who were randomly assigned to the negative information treatment viewed a 3-minute video describing the 'negative and deterministic impact' of neonicotinoids on pollinators. In the video, neonicotinoid insecticides applied to crops and landscapes were described as one of the leading causes for the bee population declines by a university professor. News titles such as 'Pesticides killing bees 
- study founds neonicotinoid pesticides harm bees: Science' were displayed. ${ }^{2}$ Survey webpage viewing duration restrictions were set up to ensure survey respondents watched the entire video. We anticipated the negative information treatment would significantly impact respondents' choices of plants.

\section{- Balanced information}

On the other hand, survey respondents randomly assigned to the balanced information treatment viewed a 3-minute video with a 'neutral' position toward neonicotinoids. In the video, the potential risks of neonicotinoids to pollinators were discussed. However, respondents were informed that the causes of Colony Collapse Disorder and pollinator declines are complex and scientific evidence is inconclusive and provisional regarding the relationship between neonicotinoids and pollinator health.

The balanced information treatment aimed to provide a broader understanding of neonicotinoids, as opposed to the strictly negative, unidirectional media bias, and further test respondents' responses to relatively objective information. The video began with an individual beekeeper who believed neonicotinoids are toxic to bees. It then transited to an academic presentation showing neonicotinoids cannot be implicated in honeybee declines given existing scientific evidence. There are discrepancies in government policies regarding the use of neonicotinoids in different countries. The video concluded with remarks that causes of bee health issues are complicated. ${ }^{3}$ Similar to the cognitive process for biotechnology and GM foods, existing public awareness of neonicotinoids can be escalated by negative media coverage that excludes information from studies that reported inconclusive or conflicting results. The impact of media coverage of biotechnology and other new food technologies on public perceptions has been well documented (Bauer, 2005; Cook et al., 2006; Frewer et al., 2002; Marks et al., 2007; Vilella-Vila and Costa-Font, 2008). Using a balanced information treatment, we attempt to check the potential negative media bias induced by the negative information treatment.

\subsection{Data}

The national online survey was conducted in 2018 using Qualtrics survey software. A national sample that consisted of 1,260 participants who were evenly distributed among the control group and two information treatment groups ( $\mathrm{n}=420$ per group). The average age of the participants was 52 years old with a median of 56 . Compared to the general U.S. population statistics, our sample appeared to overrepresent older age individuals. However, they are the core consumers for lawn and garden products who are 45 years old and older (National Gardening Association, 2019). Specifically, the age group of 55-64 years old reported the highest spending on lawn and garden products and also exhibited the largest growth in spending on lawn and gardening activities in 2018. Male participants accounted for $42 \%$ of the sample. The majority of participants were Caucasian (87\%), followed by African American (5\%), Hispanic (3\%), and Asian (3\%). Caucasian population was slightly oversampled in our data comparing with the national estimate of $75 \%$. The average household size was relatively small, consisting of two to three people. $26 \%$ of the survey respondents indicated they have children under 18 in their households, and 31\% lived in rural areas. $73 \%$ of respondents reported their annual income level was between $\$ 20,000-100,000$. Almost all participants reported that they were high school graduates, and more than half of the participants had a Bachelor's degree or higher level of education (Table 1).

The sampled population was not knowledgeable about neonicotinoids, with only $27 \%$ of the respondents (344 respondents) reporting that they had heard about neonicotinoid insecticides. Among those who heard about neonicotinoids, only 212 participants ( $17 \%$ of the total sample) indicated that they were knowledgeable about neonicotinoids by selecting a four or higher on the 7-point Likert knowledge scale. ${ }^{4}$ This finding is consistent with previous studies reporting on public knowledge about neonicotinoids. In addition, four quiz questions were used to measure participants' objective knowledge about pollinator attractive plants. In each quiz question, participants were provided two plant names supplemented with images of the plants

\footnotetext{
${ }^{2}$ The video can be accessed at https://youtu.be/Rp0N3oIngfg

${ }^{3}$ The video can be accessed at https://youtu.be/ACfecfdDmN8

${ }^{4}$ The knowledge question had a 7-point Likert scale with 1 indicating 'not at all knowledgeable' and 7 indicating 'extremely knowledgeable.'
} 
Table 1. Summary statistics for survey respondents.

\begin{tabular}{|c|c|c|}
\hline Variables & Sample estimates & U.S. population estimates ${ }^{1}$ \\
\hline Number of respondents & 1,260 & $263,534,161^{2}$ \\
\hline \multicolumn{3}{|l|}{ Age } \\
\hline Mean & 52.4 & - \\
\hline Median & 56 & 38.5 \\
\hline Average household size & 2.70 & 2.62 \\
\hline Male & $42.4 \%$ & $49.2 \%$ \\
\hline Children under 18 in the household & $27.1 \%$ & $26.1 \%$ \\
\hline \multicolumn{3}{|l|}{ Household income } \\
\hline Less than $\$ 99,999$ & $83.6 \%$ & $68.6 \%$ \\
\hline Less than $\$ 19,999$ & $10.7 \%$ & \\
\hline$\$ 20,000-39,999$ & $22.7 \%$ & \\
\hline$\$ 40,000-59,999$ & $22.7 \%$ & \\
\hline$\$ 60,000-79,999$ & $16.3 \%$ & \\
\hline$\$ 80,000-99,999$ & $11.2 \%$ & \\
\hline$\$ 100,000$ or more & $16.4 \%$ & $31.4 \%$ \\
\hline$\$ 100,000-119,999$ & $6.75 \%$ & \\
\hline More than $\$ 120,000$ & $9.68 \%$ & \\
\hline Median & $\$ 40,000-59,999$ & $\$ 65,712$ \\
\hline Mean & $\$ 60,000-79,999$ & $\$ 92,324$ \\
\hline \multicolumn{3}{|l|}{ Education level } \\
\hline Some high school & $1.35 \%$ & $12.4 \%$ \\
\hline High school diploma / GED & $17.3 \%$ & $26.9 \%$ \\
\hline Some college & $24.4 \%$ & $20.0 \%$ \\
\hline 2 year or Associate's degree & $15.4 \%$ & $8.6 \%$ \\
\hline 4 year Bachelor's degree & $24.6 \%$ & $20.3 \%$ \\
\hline A graduate or professional's degree & $16.9 \%$ & $12.8 \%$ \\
\hline \multicolumn{3}{|l|}{ Ethnicity } \\
\hline White & $86.9 \%$ & $75.0 \%$ \\
\hline African American & $5.08 \%$ & $14.2 \%$ \\
\hline Hispanic $^{3}$ & $2.78 \%$ & $18.4 \%{ }^{\mathrm{c}}$ \\
\hline Asian & $2.78 \%$ & $6.8 \%$ \\
\hline Native American & $0.87 \%$ & $1.7 \%$ \\
\hline Pacific Islander & $0.16 \%$ & $0.4 \%$ \\
\hline Other & $1.43 \%$ & $5.5 \%$ \\
\hline Rural (\%) & $31.0 \%$ & - \\
\hline
\end{tabular}

12019 American community survey 1-year estimates for U.S. population (US Census Bureau, 2019).

2 Estimates for population 16 years and over.

${ }^{3}$ The category of Hispanic may be of any race and includes other race categories.

and selected the one that was pollinator attractive. Detailed distributions of survey respondents' prior beliefs and knowledge about neonicotinoids, pollinator attractive plants, as well as their labeling preferences (by treatment group), are presented in Table 2. On average, participants in the control group were slightly less knowledgeable about neonicotinoids $(\mathrm{M}=2.21)$ and pollinator attractive plants $(\mathrm{M}=1.67)$. They also perceived the disclosure of 'pesticide free' $(\mathrm{M}=5.70)$ and 'neonicotinoid free' $(\mathrm{M}=4.97)$ on a plant label as less important when compared to the two treatment groups. A direct $\mathrm{M}$ comparison suggests that participants in the control group were slightly less knowledgeable than those in the negative treatment or balanced treatment groups (with $P$-values smaller than 0.01$).{ }^{5}$ Nonetheless, tested objective knowledge about pollinator attractive

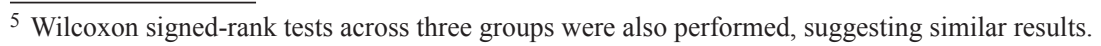


plants across three groups are similar (with $P$-values greater than 0.1 ). The control and two information treatment groups also possess similar perceptions about the importance of disclosing 'pesticide free' and 'neonicotinoid free' on the label (Table 2), which indicates participants' prior beliefs and knowledge were relatively homogenous, which is necessary for the validity of the treatment effects.

Table 2. Frequency distribution on knowledge about neonicotinoids and labeling preference. ${ }^{1}$

\begin{tabular}{|c|c|c|c|c|c|c|c|}
\hline \multirow[t]{2}{*}{ Variable } & & \multicolumn{2}{|l|}{ Control (0) } & \multicolumn{2}{|c|}{ Negative treatment (1) } & \multicolumn{2}{|c|}{ Balanced treatment (2) } \\
\hline & & Frequency & $\begin{array}{l}\text { Percentage } \\
(\%)\end{array}$ & Frequency & $\begin{array}{l}\text { Percentage } \\
(\%)\end{array}$ & Frequency & $\begin{array}{l}\text { Percentage } \\
(\%)\end{array}$ \\
\hline \multirow{9}{*}{$\begin{array}{l}\text { Knowledge } \\
\text { of neo- } \\
\text { nicotinoids }^{2}\end{array}$} & $1=$ not at all knowledgeable & 242 & 57.62 & 213 & 50.71 & 191 & 45.48 \\
\hline & 2 & 51 & 12.14 & 41 & 9.76 & 48 & 11.43 \\
\hline & 3 & 20 & 4.76 & 27 & 6.43 & 25 & 5.95 \\
\hline & 4 & 50 & 11.90 & 53 & 12.62 & 68 & 16.19 \\
\hline & 5 & 29 & 6.90 & 40 & 9.52 & 50 & 11.90 \\
\hline & 6 & 15 & 3.57 & 23 & 5.48 & 25 & 5.95 \\
\hline & $7=$ extremely knowledgeable & 13 & 3.10 & 23 & 5.48 & 13 & 3.10 \\
\hline & Mean (std. dev.) & \multicolumn{2}{|l|}{$2.21(1.74)$} & \multicolumn{2}{|l|}{$2.59(1.96)$} & \multicolumn{2}{|l|}{$2.68(1.87)$} \\
\hline & \multicolumn{3}{|l|}{ Paired $t$-test } & \multicolumn{2}{|c|}{$-2.93(P$-value $=0.00)$} & \multicolumn{2}{|c|}{$-3.72(P$-value $=0.00)$} \\
\hline \multirow{7}{*}{$\begin{array}{l}\text { Knowledge } \\
\text { about } \\
\text { pollinator } \\
\text { attractive } \\
\text { plants }^{3}\end{array}$} & $0=$ none correct & 61 & 14.52 & 50 & 11.90 & 52 & 12.38 \\
\hline & $1=$ one answer correct & 109 & 25.95 & 130 & 30.95 & 117 & 27.86 \\
\hline & $2=$ two answers correct & 170 & 40.48 & 156 & 37.14 & 154 & 36.37 \\
\hline & $3=$ three answers correct & 67 & 15.95 & 67 & 15.95 & 76 & 18.10 \\
\hline & $4=$ all four answers correct & 13 & 3.10 & 17 & 4.05 & 21 & 5.00 \\
\hline & Mean (std. dev.) & \multicolumn{2}{|l|}{$1.67(1.01)$} & \multicolumn{2}{|l|}{$1.69(1.01)$} & \multicolumn{2}{|l|}{$1.75(1.05)$} \\
\hline & \multicolumn{3}{|l|}{ Paired $t$-test } & \multicolumn{2}{|c|}{$-0.31(P$-value $=0.76)$} & \multicolumn{2}{|c|}{$-1.17(P$-value $=0.24)$} \\
\hline \multirow{9}{*}{$\begin{array}{l}\text { Importance of } \\
\text { 'pesticide free' } \\
\text { disclosed on a } \\
\text { plant label }^{4}\end{array}$} & $1=$ very unimportant & 22 & 5.24 & 25 & 5.95 & 29 & 6.90 \\
\hline & 2 & 9 & 2.14 & 3 & 0.71 & 8 & 1.90 \\
\hline & 3 & 13 & 3.10 & 7 & 1.67 & 10 & 2.38 \\
\hline & 4 & 37 & 8.81 & 23 & 5.48 & 39 & 9.29 \\
\hline & 5 & 54 & 12.86 & 61 & 14.52 & 54 & 12.86 \\
\hline & 6 & 96 & 22.86 & 108 & 25.71 & 74 & 17.62 \\
\hline & $7=$ very important & 189 & 45.00 & 193 & 45.95 & 206 & 49.05 \\
\hline & Mean (std. dev.) & \multicolumn{2}{|l|}{$5.70(1.67)$} & \multicolumn{2}{|l|}{$5.83(1.60)$} & \multicolumn{2}{|l|}{$5.68(1.77)$} \\
\hline & \multicolumn{3}{|l|}{ Paired $t$-test } & \multicolumn{2}{|c|}{$-1.10(P$-value $=0.27)$} & \multicolumn{2}{|c|}{$-0.18(P$-value $=0.87)$} \\
\hline Importance of & $1=$ strongly disagree & 17 & 4.05 & 19 & 4.52 & 25 & 5.95 \\
\hline 'neonicotinoid & 2 & 12 & 2.86 & 10 & 2.38 & 19 & 4.52 \\
\hline free' disclosed & 3 & 14 & 3.33 & 16 & 3.81 & 13 & 3.10 \\
\hline on a plant & $4=$ neither agree nor disagree & 151 & 35.95 & 135 & 32.14 & 121 & 28.81 \\
\hline \multirow[t]{5}{*}{ label $^{5}$} & 5 & 64 & 15.24 & 64 & 15.24 & 45 & 10.71 \\
\hline & 6 & 54 & 12.86 & 72 & 17.14 & 67 & 15.95 \\
\hline & 7 & 108 & 25.71 & 104 & 24.76 & 130 & 30.95 \\
\hline & Mean (std. dev.) & $4.97(1.60)$ & & $5.02(1.61)$ & & $5.05(1.78)$ & \\
\hline & \multicolumn{3}{|l|}{ Paired $t$-test } & $-0.43(P-\mathrm{val}$ & $u e=0.67)$ & $-0.73(P$-val & $e=0.46)$ \\
\hline
\end{tabular}

${ }^{1}$ The sample size is the same for the control, negative and balanced information treatment groups. Each group consists of 420 participants. Wilcoxon signed-rank test provides similar results and are suppressed from the table.

${ }^{2}$ Knowledge of neonicotinoids summarizes participants' self-reported knowledge on a 7-point Likert scale.

${ }^{3}$ Knowledge about pollinator attractive plants summarizes participants' answers to four quiz questions. In each quiz question, participants were provided two plant names supplemented with plant images and were asked to select one that was pollinator attractive. ${ }^{4}$ Importance of 'pesticide free' disclosed on a plant label summarizes participants' self-reported information on a 7-point Likert scale.

${ }^{5}$ Importance of 'neonicotinoid free' disclosed on a plant label summarizes participants' self-reported information on a 7-point Likert scale. 
Given that prior knowledge has a potential to affect participants' interpretation of information (Frewer et al., 1999; McCluskey et al., 2016; McFadden and Lusk, 2015; Poortinga and Pidgeon, 2004), we categorize survey respondents into two groups: knowledgeable and not knowledgeable groups. Given the sensitivity of the topic, participants may have provided socially desirable answers by reporting themselves as more 'aware' or 'knowledgeable' about pollinators and neonicotinoids than they actually are. Studies have shown that consumers may overstate their knowledge (Fernbach et al., 2019). To circumvent the potential bias rooted in self-reported information, the two groups were based on individual's objective knowledge about pollinator attractive plants, which can be directly linked with individual's knowledge about neonicotinoid insecticides. The mean and median values of respondents' objective knowledge are 1.7 and 2 respectively (i.e. correctly answered two quiz questions), but only $20 \%$ of the sample correctly answered three or all quiz questions. Therefore, we used correctly answering three quiz questions (which is above both the mean and median knowledge) as a cut point to divide respondents into knowledge groups. Respondents were defined as knowledgeable about pollinator attractive plants if they correctly answered at least three quiz questions (K-group), and not knowledgeable about pollinator attractive plants if they correctly answered two or fewer quiz questions (NK-group).

\subsection{Econometric models}

In a typical choice experiment, respondents are presented with a series of decision scenarios and asked to state their most preferred choice among multiple product profiles in each choice scenario (Swait and Adamowicz, 2001). This structure yields a set of panel observations of stated choices for each individual and thus makes individual characteristics secondary to examined product attributes to explore heterogeneity involved in choices (Fennell et al., 2003). Mixed logit models, which allow for random taste variation, unrestricted substitution patterns (i.e. relaxes the IIA assumption in the family of logit models), and correlation in unobserved factors, are considered the most promising modeling tool for studying discrete choices (Train, 2009).

McFadden and Train (2000) showed that mixed logit models are highly flexible to accommodate any random utility model. Assuming the utility that individual $i$ derives from choosing alternative $j$ in choice scenario $s$ has the following functional form:

$$
U_{i j s}=V_{i j t}\left(x_{i j s}, \beta_{i}\right)+\varepsilon_{n j s}
$$

where, $V_{n j s}$ is a function of observed factors (to the researcher) affecting the decision-maker's utility and often is assumed to be linear in $\beta$, i.e. $V_{i j s}=\beta_{i}^{\prime} x_{i j s}$. See Table 3 for a list of the variables and their definitions. $\varepsilon_{i j s}$ captures all the factors unobservable and is assumed to satisfy iid Type I extreme value distribution. $\beta_{i}$ is drawn from the distribution $f(\beta \mid \theta)$ with underlying parameters $\theta$. Along with $\varepsilon_{i j s}$, the $\beta_{i}$ captures variations in preferences among individuals. Conditional on $\beta_{i}$, the probability that person $i$ chooses alternative $j$ in choice scenario $s$ is standard logit:

$$
L_{i j s}\left(\beta_{i}\right)=\exp \left(\beta_{i}^{\prime} x_{i j s}\right) / \sum_{k} \exp \left(\beta_{i}^{\prime} x_{i k s}\right)
$$

In repeated choices, denote $j(i, s)$ the alternative that person $i$ chooses in scenario $s$. Conditional on $\beta_{i}$, the probability of person $i$ 's observed sequence of choices is the product of standard logit in Equation 2:

$$
P_{i}\left(\beta_{i}\right)=\prod_{s} L_{i j(i, s) s}\left(\beta_{i}\right)
$$

The unconditional probability for the sequence of choices is:

$$
P_{i}\left(\theta^{*}\right)=\int P_{i}\left(\beta_{i}\right) f\left(\beta_{i} \mid \theta^{*}\right) d \beta_{i}
$$

Where $f\left(\beta_{i} \mid \theta^{*}\right)$ is the density of $\beta_{i}$ with parameter $\theta^{*}$. 
The log-likelihood function is $L L\left(\theta^{*}\right)=\sum_{i} \ln P_{i}\left(\theta^{*}\right)$. The maximum likelihood estimation is obtained through simulation by maximizing the simulated log-likelihood function (see Revelt and Train (1998) for more detailed simulation process).

With the set of attributes and attribute levels described in Table 3, the underlying utility structure for our empirical estimation can be specified as follows:

$$
\begin{aligned}
& U_{i j s}=\beta_{0} \text { Optout }_{i j s}+\boldsymbol{\beta}_{1} \text { Plant }_{i j s}+\beta_{2} \text { Free_text }_{i j s}+\beta_{3} \text { Free_logo }_{i j s}+\beta_{4} \text { Neonic_treat }_{i j s} \\
& +\beta_{5} \text { Bio_pot }_{i j s}+\beta_{6} \text { Price }_{i j s}+\varepsilon_{i j s}
\end{aligned}
$$

where 'Optout' is an indicator variable that takes the value of 1 if a participant chose to buy neither of the plants and 0 if a participant chose either product profile (plant A or plant B). 'Plant' is a vector of plant dummies indicating the plant type. Using 'protected from problematic pests by neonicotinoids' as the baseline attribute level, three binary variables 'Free_text', 'Free_logo', and 'Neonic_treat' capture consumer preferences for 'neonicotinoid free', 'bee better certified', and 'treated with neonicotinoids' labels, respectively. 'Bio_pot' is another binary variable representing the type of container presented in each option, which equals 1 if the scenario contains a biodegradable container and zero for a conventional plastic container. 'Price' is the price of a plant in each option. The price coefficient $\beta_{6}$ is treated as a non-random variable. Coefficients for all other variables are treated as random variables and are assumed to have normal distributions. Equation 5 is estimated using a maximum simulated likelihood estimation. Based on the estimated coefficients, the mean WTP value for a change in attribute is calculated as the negative ratio of the mean estimated coefficient associated with the attribute and the price coefficient using the delta method.

\begin{tabular}{|c|c|}
\hline Variable & Definition \\
\hline Price & A continuous variable representing actual plant price. \\
\hline Optout & $\begin{array}{l}\text { Alternative representing the utility associated with choosing to } \\
\text { buy neither of the plants. }\end{array}$ \\
\hline \multicolumn{2}{|c|}{ Presence or absence of neonicotinoid in labels } \\
\hline Free_text & Binary, 1 if a plant is labeled as 'neonicotinoid free' (text). \\
\hline Free_logo & Binary, 1 if a plant is labeled as 'bee better certified' (logo). \\
\hline Neonic_treat & Binary, 1 if a plant is labeled as 'treated with neonicotinoids'. \\
\hline Neonic_protect & $\begin{array}{l}\text { Binary, } 1 \text { if a plant is labeled as 'protected from problematic pests } \\
\text { by neonicotinoids'. }\end{array}$ \\
\hline \multicolumn{2}{|r|}{ ens } \\
\hline Impatiens & Binary, 1 if the plant is Impatiens (annual). \\
\hline Marigold & Binary, 1 if the plant is Marigold (annual). \\
\hline Pentas & Binary, 1 if the plant is Pentas (annual). \\
\hline Dianthus & Binary, 1 if the plant is Dianthus (perennial). \\
\hline Mum & Binary, 1 if the plant is Chrysanthemums (perennial). \\
\hline Salvia & Binary, 1 if the plant is Salvia (perennial). \\
\hline \multicolumn{2}{|l|}{ Container type } \\
\hline Bio_pot & Binary, 1 if the container is biodegradable. \\
\hline \multicolumn{2}{|l|}{ Information treatment } \\
\hline Control & No additional information was provided. \\
\hline Negative information treatment & $\begin{array}{l}\text { A short video describing the negative impacts of neonicotinoids } \\
\text { on bees and pollinators was displayed. }\end{array}$ \\
\hline Balanced information treatment & $\begin{array}{l}\text { A short video describing neutral impacts including existing } \\
\text { scientific evidence of neonicotinoids on bees and pollinators was } \\
\text { displayed. }\end{array}$ \\
\hline
\end{tabular}

Table 3. Description of model variables. 


\section{Results}

The mixed logit model was run separately for annual and perennial plants. The main interest was the coefficients associated with labels disclosing the absence or presence of neonicotinoids. Results from the mixed logit model for the control and two information treatment groups provide the direction and magnitude of consumer preferences for different plant attributes (Supplementary Table S2 and S3). ${ }^{6}$ The coefficients indicate the mean level of consumer preferences while the standard deviations reflect the presence of variation in consumer preferences. A quick comparison between Supplementary Tables S2 and S3 show that across all control and treatment groups, the estimated coefficients for annual bedding plants and perennial plants were consistent in both direction and magnitude. Participants were less likely to choose a plant with a higher price, consistent with demand theory. The negative and significant $\beta_{\text {optout }}$ indicates that choosing one of the plants (either plant A or B) produced a higher utility level than not choosing any of the options. Regardless of the treatments received, survey respondents preferred labels disclosing the absence of neonicotinoids and biodegradable containers. For annual plants, survey respondents preferred impatiens over the alternatives, while for perennial plants, participants preferred chrysanthemums. These general patterns did not change when dividing the sample into different knowledge groups (Table 4 and 5). Negative information has larger impact on both knowledge groups comparing to balanced information treatment. ${ }_{6}^{6}$ Supplementary Table S2 summarizes the estimated results for annual bedding plants only. Supplementary Table S3 summarizes the
results for perennial plants only.

Table 4. Estimates from the mixed logit model by knowledge groups for annual plants (4-inch container). ${ }^{1}$

\begin{tabular}{|c|c|c|c|c|c|c|}
\hline & \multicolumn{6}{|l|}{ K-group ${ }^{2}$} \\
\hline & \multicolumn{2}{|l|}{ Control } & \multicolumn{2}{|c|}{ Negative treatment } & \multicolumn{2}{|c|}{ Balanced treatmen } \\
\hline & Estimates & SE & Estimates & SE & Estimates & SE \\
\hline$\beta_{\text {price }}$ & $-0.224^{* * *}$ & 0.076 & $-0.245^{* *}$ & 0.099 & $-0.267^{* * *}$ & 0.079 \\
\hline$\beta_{\text {optout }}$ & $-1.525^{* * *}$ & 0.471 & 0.121 & 0.421 & $-1.726^{* * *}$ & 0.482 \\
\hline$\sigma_{\text {optout }}$ & $1.482^{* * *}$ & 0.420 & $1.499^{* * *}$ & 0.361 & $2.107^{* * *}$ & 0.295 \\
\hline \multicolumn{7}{|c|}{ Neonicotinoid labeling (Neonic_protect) } \\
\hline$\beta_{\text {free_text }}$ & $1.183^{* * *}$ & 0.223 & $3.579^{* * *}$ & 0.430 & $2.322^{* * *}$ & 0.312 \\
\hline$\sigma_{\text {free_text }}$ & 0.641 & 0.391 & $1.700^{* * *}$ & 0.332 & $2.084^{* * *}$ & 0.339 \\
\hline$\beta_{\text {free_logo }}$ & $2.557^{* * *}$ & 0.328 & $3.910^{* * *}$ & 0.456 & $2.815^{* * *}$ & 0.391 \\
\hline$\sigma_{\text {free_logo }}$ & $1.184^{* * *}$ & 0.414 & $2.647^{* * *}$ & 0.580 & $2.252^{* * *}$ & 0.352 \\
\hline$\beta_{\text {neonic_treat }}$ & -0.191 & 0.293 & $-1.212^{* *}$ & 0.562 & $-0.558^{*}$ & 0.313 \\
\hline$\sigma_{\text {neonic_treat }}$ & $1.010^{* *}$ & 0.434 & $1.951^{* * *}$ & 0.495 & $-1.129^{* * *}$ & 0.397 \\
\hline \multicolumn{7}{|c|}{ Container (Conventional) } \\
\hline$\beta_{\text {bio_pot }}$ & $0.421^{* * *}$ & 0.164 & 0.256 & 0.219 & $0.451^{* *}$ & 0.188 \\
\hline$\sigma_{b i o \_p o t}$ & 0.312 & 0.384 & $-0.448^{*}$ & 0.264 & $-0.861^{* * *}$ & 0.230 \\
\hline \multicolumn{7}{|c|}{ Plant type (Impatiens) } \\
\hline$\beta_{\text {marigold }}$ & -0.305 & 0.222 & $-0.564^{* *}$ & 0.235 & $-0.589^{* * *}$ & 0.216 \\
\hline$\sigma_{\text {marigold }}$ & $1.013^{* * *}$ & 0.263 & -0.495 & 0.375 & $0.934^{* * *}$ & 0.279 \\
\hline$\beta_{\text {pentas }}$ & -0.334 & 0.237 & $-0.589^{*}$ & 0.326 & -0.286 & 0.235 \\
\hline$\sigma_{\text {pentas }}$ & $-0.765^{* * *}$ & 0.288 & $1.249^{* * *}$ & 0.359 & -0.037 & 0.350 \\
\hline Log-likelihood & -470.22 & & -430.03 & & -535.85 & \\
\hline Observations & 1,920 & & 2,016 & & 2,382 & \\
\hline
\end{tabular}


Table 4. Continued.

\begin{tabular}{|c|c|c|c|c|c|c|}
\hline & \multicolumn{6}{|l|}{ NK-group ${ }^{2}$} \\
\hline & \multicolumn{2}{|l|}{ Control } & \multicolumn{2}{|c|}{ Negative treatment } & \multicolumn{2}{|c|}{ Balanced treatmen } \\
\hline & Estimates & SE & Estimates & SE & Estimates & SE \\
\hline$\beta_{\text {price }}$ & $-0.423^{* * *}$ & 0.039 & $-0.374^{* * *}$ & 0.048 & $-0.390^{* * *}$ & 0.045 \\
\hline$\beta_{\text {optout }}$ & $-1.761^{* * *}$ & 0.201 & -0.046 & 0.203 & $-0.952^{* * *}$ & 0.220 \\
\hline$\sigma_{\text {optout }}$ & $1.974^{* * *}$ & 0.158 & $1.110^{* * *}$ & 0.145 & $1.899^{* * *}$ & 0.213 \\
\hline \multicolumn{7}{|c|}{ Neonicotinoid labeling (Neonic_protect) } \\
\hline$\beta_{\text {free text }}$ & $1.447^{* * *}$ & 0.141 & $3.359^{* * *}$ & 0.167 & $2.668^{* * *}$ & 0.166 \\
\hline$\sigma_{\text {free_text }}$ & $1.484^{* * *}$ & 0.142 & $0.811^{* * *}$ & 0.205 & $1.598^{* * *}$ & 0.160 \\
\hline$\beta_{\text {free } \operatorname{logo}}$ & $2.439^{* * *}$ & 0.169 & $4.157^{* * *}$ & 0.208 & $3.189^{* * *}$ & 0.205 \\
\hline$\sigma_{\text {free }} \log _{o}$ & $1.592^{* * *}$ & 0.204 & $1.398^{* * *}$ & 0.235 & $1.964^{* * *}$ & 0.224 \\
\hline$\beta_{\text {neonic treat }}$ & $-0.275^{* *}$ & 0.121 & $-0.951^{* * *}$ & 0.335 & -0.196 & 0.162 \\
\hline$\sigma_{\text {neonic treat }}$ & -0.240 & 0.331 & $2.426^{* * *}$ & 0.308 & $0.909^{* * *}$ & 0.246 \\
\hline \multicolumn{7}{|c|}{ Container (Conventional) } \\
\hline$\beta_{\text {bio pot }}$ & $0.594^{* * *}$ & 0.090 & $0.370^{* * *}$ & 0.097 & $0.347^{* * *}$ & 0.095 \\
\hline$\sigma_{\text {bio pot }}$ & $0.616^{* * *}$ & 0.156 & -0.043 & 0.239 & $-0.381^{* *}$ & 0.151 \\
\hline \multicolumn{7}{|c|}{ Plant type (Impatiens) } \\
\hline$\beta_{\text {marigold }}$ & $-0.563^{* * *}$ & 0.104 & $-0.479^{* * *}$ & 0.118 & $-0.552^{* * *}$ & 0.113 \\
\hline$\sigma_{\text {marigold }}$ & $0.917^{* * *}$ & 0.122 & $-0.452^{* *}$ & 0.181 & $0.738^{* * *}$ & 0.191 \\
\hline$\beta_{\text {pentas }}$ & $-0.564^{* * *}$ & 0.116 & $-0.492^{* * *}$ & 0.137 & $-0.309^{* *}$ & 0.130 \\
\hline$\sigma_{\text {pentas }}$ & $0.857^{* * *}$ & 0.190 & $0.885^{* * *}$ & 0.158 & $0.527^{* * *}$ & 0.196 \\
\hline Log-likelihood & $-2,116.91$ & & $-1,603.14$ & & $-1,800.81$ & \\
\hline Observations & 8,160 & & 8,064 & & 7,752 & \\
\hline
\end{tabular}

$1 * * *, * *$, and $*$ represent significance level at the 1,5 and $10 \%$, respectively. Attributes used as base groups are in brackets. $\mathrm{SE}=$ standard error.

${ }^{2}$ K-group = knowledgeable about pollinator attractive plants; NK-group = not knowledgeable about pollinator attractive plants.

Table 5. Estimates from the mixed logit model by knowledge groups for perennial plants (1-gallon container). ${ }^{1}$

\begin{tabular}{|c|c|c|c|c|c|c|}
\hline & \multicolumn{6}{|l|}{ K-group ${ }^{2}$} \\
\hline & \multicolumn{2}{|l|}{ Control } & \multicolumn{2}{|c|}{ Negative treatment } & \multicolumn{2}{|c|}{ Balanced treatmen } \\
\hline & Estimates & SE & Estimates & SE & Estimates & SE \\
\hline$\overline{\beta_{\text {price }}}$ & $-0.280^{* * *}$ & 0.061 & $-0.358^{* * *}$ & 0.075 & $-0.619^{* * *}$ & 0.070 \\
\hline$\beta_{\text {optout }}$ & $-2.613^{* * *}$ & 0.592 & -0.690 & 0.610 & $-3.775^{* * *}$ & 0.543 \\
\hline$\sigma_{\text {optout }}$ & $1.792^{* * *}$ & 0.318 & $1.194^{* * *}$ & 0.381 & $1.796^{* * *}$ & 0.264 \\
\hline \multicolumn{7}{|c|}{ Neonicotinoid labeling (Neonic_protect) } \\
\hline$\beta_{\text {free_text }}$ & $0.974^{* * *}$ & 0.277 & $3.631^{* * *}$ & 0.461 & $2.279^{* * *}$ & 0.303 \\
\hline$\sigma_{\text {free_text }}$ & $-0.865^{* * *}$ & 0.410 & 1.365 & 0.853 & $1.828^{* * *}$ & 0.384 \\
\hline$\beta_{\text {free_logo }}$ & $2.978^{* * *}$ & 0.414 & $4.780^{* * *}$ & 0.531 & $3.681^{* * *}$ & 0.396 \\
\hline$\sigma_{\text {free_logo }}$ & $2.054^{* * *}$ & 0.561 & $1.934^{* * *}$ & 0.682 & $2.160^{* * *}$ & 0.340 \\
\hline$\beta_{\text {neonic_treat }}$ & $-0.799^{* * *}$ & 0.304 & -0.690 & 0.528 & $-1.501^{* * *}$ & 0.414 \\
\hline$\sigma_{\text {neonic_treat }}$ & $-1.073^{* * *}$ & 0.387 & $2.644^{* * *}$ & 0.530 & $1.925^{* * *}$ & 0.366 \\
\hline \multicolumn{7}{|c|}{ Container (Conventional) } \\
\hline$\beta_{\text {bio_pot }}$ & $0.431 *$ & 0.221 & $1.268^{* * *}$ & 0.455 & $0.984^{* * *}$ & 0.214 \\
\hline$\sigma_{\text {bio_pot }}$ & $0.741^{*}$ & 0.383 & $1.182^{* *}$ & 0.498 & $-0.948^{* * *}$ & 0.220 \\
\hline \multicolumn{7}{|c|}{ Plant type (Dianthus) } \\
\hline$\beta_{\text {mum }}$ & $0.994^{* * *}$ & 0.363 & 0.232 & 0.312 & $1.050^{* * *}$ & 0.230 \\
\hline$\sigma_{m u m}$ & $2.097^{* * *}$ & 0.384 & $1.825^{* * *}$ & 0.390 & $1.325^{* * *}$ & 0.244 \\
\hline$\beta_{\text {salvia }}$ & $0.778^{* * *}$ & 0.359 & 0.578 & 0.387 & 0.405 & 0.269 \\
\hline$\sigma_{\text {salvia }}$ & $1.469^{* * *}$ & 0.393 & $1.689^{* *}$ & 0.735 & -0.259 & 0.392 \\
\hline Log-likelihood & -473.14 & & -422.01 & & -532.05 & \\
\hline Observations & 1,920 & & 2,016 & & 2,328 & \\
\hline
\end{tabular}


Table 5. Continued.

\begin{tabular}{|c|c|c|c|c|c|c|}
\hline & \multicolumn{6}{|l|}{ NK-group $^{2}$} \\
\hline & \multicolumn{2}{|l|}{ Control } & \multicolumn{2}{|c|}{ Negative treatment } & \multicolumn{2}{|c|}{ Balanced treatment } \\
\hline & Estimates & SE & Estimates & SE & Estimates & SE \\
\hline$\beta_{\text {price }}$ & $-0.433^{* * *}$ & 0.030 & $-0.373^{* * *}$ & 0.034 & $-0.338^{* * *}$ & 0.031 \\
\hline$\beta_{\text {optout }}$ & $-2.953^{* * *}$ & 0.264 & -1.270 & 0.279 & $-1.431^{* * *}$ & 0.264 \\
\hline$\sigma_{\text {optout }}$ & $2.255^{* * *}$ & 0.188 & $1.676^{* * *}$ & 0.165 & $1.461^{* * *}$ & 0.140 \\
\hline \multicolumn{7}{|c|}{ Neonicotinoid labeling (Neonic_protect) } \\
\hline$\beta_{\text {free_text }}$ & $1.270^{* * *}$ & 0.169 & $3.249^{* * *}$ & 0.198 & $2.462^{* * *}$ & 0.160 \\
\hline$\sigma_{\text {free_text }}$ & $2.244^{* * *}$ & 0.188 & $1.877^{* * *}$ & 0.201 & $-1.370^{* * *}$ & 0.228 \\
\hline$\beta_{\text {free_logo }}$ & $2.798^{* * *}$ & 0.202 & $4.256^{* * *}$ & 0.228 & $3.255^{* * *}$ & 0.179 \\
\hline$\sigma_{\text {free_logo }}$ & $2.388^{* * *}$ & 0.207 & $1.973^{* * *}$ & 0.244 & $1.402^{* * *}$ & 0.191 \\
\hline$\beta_{\text {neonic_treat }}$ & $-0.466^{* * *}$ & 0.128 & $-0.651^{* * *}$ & 0.233 & $-1.037^{* * *}$ & 0.265 \\
\hline$\sigma_{\text {neonic_treat }}$ & $0.378^{*}$ & 0.207 & $1.709^{* * *}$ & 0.208 & $1.765^{* * *}$ & 0.284 \\
\hline \multicolumn{7}{|c|}{ Container (Conventional) } \\
\hline$\beta_{\text {bio_pot }}$ & $0.768^{* * *}$ & 0.101 & $0.992^{* * *}$ & 0.118 & $0.818^{* * *}$ & 0.109 \\
\hline$\sigma_{\text {bio_pot }}$ & -0.138 & 0.168 & 0.015 & 0.177 & $0.456^{* *}$ & 0.214 \\
\hline \multicolumn{7}{|c|}{ Plant type (Dianthus) } \\
\hline$\beta_{\text {mum }}$ & $0.517^{* * *}$ & 0.111 & $0.219^{*}$ & 0.119 & $0.534^{* * *}$ & 0.118 \\
\hline$\sigma_{\text {mum }}$ & $1.092^{* * *}$ & 0.140 & $0.965^{* * *}$ & 0.135 & $1.231^{* * *}$ & 0.142 \\
\hline$\beta_{\text {salvia }}$ & 0.089 & 0.131 & $-0.307^{* *}$ & 0.144 & 0.025 & 0.133 \\
\hline$\sigma_{\text {salvia }}$ & $1.022^{* * *}$ & 0.326 & 0.171 & 0.370 & $-0.395^{*}$ & 0.237 \\
\hline Log-likelihood & $-2,095.35$ & & $-1,725.98$ & & $-1,827.19$ & \\
\hline Observations & 8,160 & & 8,064 & & 7,752 & \\
\hline
\end{tabular}

\subsection{Preferences for labels disclosing the absence or presence of neonicotinoids}

Comparing $\beta$ coefficients across control and treatment groups, we found that the negative information treatment had a stronger positive impact on consumer preference for labels disclosing the absence of neonicotinoids and a stronger negative impact on consumer preference for labels disclosing the presence of neonicotinoids. This is consistent with previous evidence of negativity bias (Baumeister et al., 2001). The impact is more meaningful when the $\beta$ coefficients are translated into WTP measures (Table 6).

Differentiated information treatment effects were identified for different label formats that communicated the absence or presence of neonicotinoids. For annual bedding plants, knowledgeable participants (K-group) in the control group (based on status quo knowledge) were willing to pay 5.27 dollars more for a plant labeled with a 'neonicotinoid free' text, but 11.39 dollars more for a plant with a 'bee better certified' logo, indicating a stronger preference for the logo disclosing the absence of neonicotinoids, without additional information (Table 6). On the other hand, participants' WTP for a plant 'treated with neonicotinoids' was 85 cents less compared to the base level (i.e. labeled as 'protected from problematic pests by neonicotinoids'), but not statistically significant indicating participants did not differentiate the two labels disclosing the presence of neonicotinoids. This pattern was similar to the information treatments. In the negative information treatment group, knowledgeable participants' WTP increased to 14.58 and 15.93 dollars more for labels indicating 'neonicotinoid free' and 'bee better certified' respectively, compared to the base group (i.e. labeled as 'protected from problematic pests by neonicotinoids'). With the balanced information treatment, knowledgeable participants' WTP increased to 8.68 dollars and 8.41 dollars more for labels with 'neonicotinoid free' (text) and 'bee better certified' (logo) compared with the base level. With additional information, knowledgeable participants were willing to pay more for the absence of neonicotinoids, regardless of the information type (i.e. negative or balanced). For labels disclosing the 
Table 6. Willingness-to-pay (WTP) estimates for product attributes from the mixed logit model.

\section{CE 1: annual plants}

\begin{tabular}{|c|c|c|c|c|c|c|}
\hline & \multicolumn{2}{|l|}{ Control } & \multicolumn{2}{|c|}{ Negative treatment } & \multicolumn{2}{|c|}{ Balanced treatment } \\
\hline & Mean & SE & Mean & SE & Mean & SE \\
\hline \multicolumn{7}{|l|}{ Sample total ${ }^{1}$} \\
\hline (Neonic_protect) & base & & & & & \\
\hline Free_text & $3.529^{* * *}$ & 0.395 & $9.969^{* * *}$ & 1.217 & $6.866^{* * *}$ & 0.745 \\
\hline Free_logo & $6.347^{* * *}$ & 0.607 & $12.108^{* * *}$ & 1.471 & $8.768^{* * *}$ & 0.927 \\
\hline Neonic_treat & $-0.569^{*}$ & 0.297 & $-2.630^{* * *}$ & 0.881 & -0.545 & 0.403 \\
\hline (Conventional) & base & & & & & \\
\hline Bio_pot & $1.431^{* * *}$ & 0.208 & $1.108^{* * *}$ & 0.285 & $1.063^{* * *}$ & 0.242 \\
\hline \multicolumn{7}{|l|}{$\mathrm{K}$-group ${ }^{2}$} \\
\hline (Neonic_protect) & base & & & & & \\
\hline Free_text & $5.272^{* * *}$ & 1.872 & $14.580^{* *}$ & 5.774 & $8.684^{* * *}$ & 2.662 \\
\hline Free_logo & $11.394^{* * *}$ & 3.783 & $15.926^{* *}$ & 6.440 & $10.528^{* * *}$ & 3.158 \\
\hline Neonic_treat & -0.851 & 1.372 & -4.935 & 3.102 & -2.088 & 1.402 \\
\hline (Conventional) & base & & & & & \\
\hline Bio_pot & $1.876^{* *}$ & 0.871 & 1.041 & 0.978 & $1.687^{* *}$ & 0.786 \\
\hline \multicolumn{7}{|l|}{ NK-group ${ }^{2}$} \\
\hline (Neonic_protect) & base & & & & & \\
\hline Free_text & $3.422^{* * *}$ & 0.414 & $8.977^{* * *}$ & 1.117 & $6.836^{* * *}$ & 0.793 \\
\hline Free_logo & $5.768^{* * *}$ & 0.575 & $11.108^{* * *}$ & 1.315 & $8.170^{* * *}$ & 0.942 \\
\hline Neonic_treat & $-0.651^{* *}$ & 0.298 & $-2.541^{* * *}$ & 0.965 & -0.503 & 0.424 \\
\hline (Conventional) & base & & & & & \\
\hline Bio_pot & $1.404^{* * *}$ & 0.222 & 0.990 & 0.282 & $0.888^{* * *}$ & 0.249 \\
\hline
\end{tabular}

Table 6. Continued.

\begin{tabular}{|c|c|c|c|c|c|c|}
\hline & \multicolumn{6}{|c|}{ CE 2: perennial plants } \\
\hline & \multicolumn{2}{|l|}{ Control } & \multicolumn{2}{|c|}{ Negative treatment } & \multicolumn{2}{|c|}{ Balanced treatment } \\
\hline & Mean & SE & Mean & SE & Mean & SE \\
\hline \multicolumn{7}{|l|}{ Sample total $^{1}$} \\
\hline (Neonic_protect) & base & & & & & \\
\hline Free text & $3.000^{* * *}$ & 0.373 & $8.834^{* * *}$ & 0.780 & $6.866^{* * *}$ & 0.745 \\
\hline Free_logo & $6.737^{* * *}$ & 0.547 & $11.361^{* * *}$ & 0.977 & $8.768^{* * *}$ & 0.927 \\
\hline Neonic treat & $-1.008^{* * *}$ & 0.267 & $-2.677^{* * *}$ & 0.710 & -0.545 & 0.403 \\
\hline (Conventional) & base & & & & & \\
\hline Bio_pot & $1.751^{* * *}$ & 0.221 & $2.757^{* * *}$ & 0.320 & $1.063^{* * *}$ & 0.242 \\
\hline \multicolumn{7}{|l|}{$\mathrm{K}$-group ${ }^{2}$} \\
\hline (Neonic_protect) & base & & & & & \\
\hline Free text & $3.477^{* * *}$ & 1.140 & $10.152^{* * *}$ & 2.225 & $3.684^{* * *}$ & 0.541 \\
\hline Free_logo & $10.627^{* * *}$ & 2.538 & $13.365^{* * *}$ & 2.776 & $5.950^{* * *}$ & 0.748 \\
\hline Neonic_treat & $-2.851^{* *}$ & 1.258 & -1.929 & 1.452 & $-2.426^{* * *}$ & 0.670 \\
\hline (Conventional) & & & & & & \\
\hline Bio_pot & $1.537^{*}$ & 0.794 & $3.546^{* * *}$ & 1.357 & $1.591^{* * *}$ & 0.349 \\
\hline \multicolumn{7}{|l|}{ NK-group ${ }^{2}$} \\
\hline (Neonic_protect) & base & & & & & \\
\hline Free text & $2.930^{* * *}$ & 0.409 & $8.699^{* * *}$ & 0.850 & $7.276^{* * *}$ & 0.743 \\
\hline Free logo & $6.457^{* * *}$ & 0.573 & $11.396^{* * *}$ & 1.081 & $9.619^{* * *}$ & 0.932 \\
\hline Neonic_treat & $-1.076^{* * *}$ & 0.304 & $-1.744^{* * *}$ & 0.636 & $-3.066^{* * *}$ & 0.808 \\
\hline (Conventional) & base & & & & & \\
\hline Bio_pot & $1.773^{* * *}$ & 0.236 & $2.656^{* * *}$ & 0.344 & $2.416^{* * *}$ & 0.354 \\
\hline
\end{tabular}

${ }^{1}$ WTP estimates for the sample total were computed based on regression results reported in Supplementary Tables S2 and S3.

${ }^{2}$ WTP estimates for K-group and NK-group were computed based on the regression results reported in Tables 4 and 5 . K-group and NK-group were based on participants' answers to four quiz questions. Participants were defined as knowledgeable about pollinator attractive plants (K-group) if they correctly answered at least three quiz questions, and not knowledgeable about pollinator attractive plants (NK-group) if they correctly answered two or fewer quiz questions. 
presence of neonicotinoids, knowledgeable participants had no clear distinction between the phrase of 'protected from problematic pests by neonicotinoids' and 'treated with neonicotinoids'. These findings support previously reported information effects (e.g. Bougherara and Combris, 2009; Li and McCluskey, 2017; Li et al., 2017; Lusk et al., 2004; Messer et al., 2017; Rousseau and Vranken, 2013), which postulate that providing information about the public component of a good increases participants' valuation for attributes that are perceived as beneficial. Even though the information treatments affected participants' WTP for both label categories, we find the impact on WTP is more substantial on labels disclosing the absence of neonicotinoids than on labels disclosing the presence of neonicotinoids. Not knowledgeable participants (NK-group) showed similar pattens in labels disclosing the absence of neonicotinoids. With additional information, not knowledgeable participants' WTP for 'neonicotinoid free' increased from 3.42 dollars (control) to 8.98 dollars (negative information) and 6.84 dollars (balanced information), WTP for 'bee better certified' increased from 5.77 dollars (control) to 11.11 dollars (negative information) and 8.17 dollars (balanced information). In contrast to knowledgeable participants' indifference, not knowledgeable participants slightly preferred the phrase of 'protected from problematic pests by neonicotinoids' over 'treated with neonicotinoids'. They were willing to pay 65 cents less for a plant 'treated with neonicotinoids' compared to the base level (i.e. labeled as 'protected from problematic pests by neonicotinoids') and 2.54 dollars less under negative information treatment. WTP results for perennial plants are quite similar to those obtained in annual plants (Table 6).

Echoing Campbell and Steele (2020), we confirmed that both negative and balanced information treatments significantly increased participants' preferences for labels disclosing the absence of neonicotinoids. In line with the GM food labeling preference literature, the negative information treatment was found to have a more substantial impact than the balanced information treatment likely due to negativity bias effects. In addition, we identified differentiated information treatment effects on different labeling formats with information treatments having a larger impact on labels disclosing the absence of neonicotinoids than labels disclosing the presence of neonicotinoids, particularly for participants in the knowledgeable group.

\subsection{Treatment effects by knowledge groups}

As explained above, participants were divided into K-group (knowledgeable) and NK-group (not knowledgeable) about pollinator attractive plants to investigate preferences based on prior knowledge under different information treatments. The estimated coefficients are reported in Table 4. An overview of the $\beta$ coefficients suggests that the general pattern of the information effect was maintained for individual knowledge groups. Nonetheless, as hypothesized, the information treatment had a differentiated impact on the two knowledge groups. Without additional information (i.e. under the control treatment), respondents in K-group did not differentiate between the two formats disclosing the presence of neonicotinoids. The $\beta_{\text {neonic }}$ treat was negative but barely significant at $10 \%$ significance level. On the other hand, participants in the NKgroup were clearly in favor of the phrase 'protected from problematic pests by neonicotinoids' given the negative and statistically significant $\beta_{\text {neonic treat }}$ coefficient. However, with additional negative information on neonicotinoids, participants' WTP for labels disclosing the presence of neonicotinoids (i.e. 'treated with neonicotinoids') showed a distinct pattern between the K- and NK-groups. As expected, participants in both knowledge groups increased their WTP for labels disclosing the absence of neonicotinoids, as well as their WTP for biodegradable containers. However, this pattern did not hold for the labels disclosing the presence of neonicotinoids. Compared with their counterparts in the control group (who did not differentiate between 'treated with neonicotinoids' vs 'protected from problematic pests by neonicotinoids'), knowledgeable participants decreased their WTP for labels 'treated with neonicotinoids' by 4.70 dollars with additional negative information (column 2, Table 6). A similar but smaller impact (1.64 dollars less) was observed for K-group under the balanced information treatment. Conversely, the above pattern was reversed for NKgroup. While the not knowledgeable participants in the control group were slightly in favor of 'protected from problematic pests by neonicotinoids' (i.e. willing to pay 76 cents less for 'treated by neonicotinoids' label), those in the negative information treatment group became indifferent between the two phrases disclosing the presence of neonicotinoids. The balanced information treatment did not affect the NK-group 
participants' WTP for labels disclosing the presence of neonicotinoids (compared to negative information treatment). These findings may suggest that with negative information, participants' attention (particularly knowledgeable participants' attention) toward labels disclosing the presence or absence of neonicotinoids could have been altered.

When comparing the effects of each neonicotinoid labeling format (Table 6), the results reveal a sizable disparity in mean WTP estimates between the knowledgeable and not knowledge participants in the control group. This WTP gap caused by knowledge differences was also observed in the information treatment results. In the negative information treatment, knowledgeable participants were willing to pay a higher price for the two labels disclosing the absence of neonicotinoids (i.e. 'neonicotinoids free' text and 'bee better certified' logo), but significantly less for labels disclosing the presence of neonicotinoids (i.e. 'treated with neonicotinoids'). This result suggests that knowledgeable participants were likely biased toward opposition to neonicotinoids. This negativity bias was boosted by additional negative information but largely mitigated by unbiased information during the two information treatments.

\section{Conclusions}

While the debate surrounding the use of neonicotinoid insecticides in the U.S. has been receiving more attention due to its potential risk to pollinators' health, general public knowledge about neonicotinoids remains low. In addition to the lack of public knowledge, consumer and/or producer feedback needed for policy makers to support regulatory decision regarding labeling or banning neonicotinoids has also been lacking. Thus, it is important and necessary to investigate how an informed public would react to and value additional information about neonicotinoids before conclusions on the merits of mandatory labeling or a ban can be drawn. This paper incorporated information treatments into a hypothetical choice experiment to determine if different types of information affect consumer preferences for ornamental plants produced with or without neonicotinoids by taking into consideration heterogeneity in consumers' knowledge.

First, we confirmed the negativity bias effects within this particular framework. Compared to unbiased and objective information, negative information had a more substantial effect on individuals' choice behavior. Results also suggest that existing public opinions toward neonicotinoid insecticides are likely skewed toward opposition of neonicotinoid use in production. Even though negative media coverage is more likely to impact public opinion, our study demonstrates that unbiased information can still effectively shape the public's perceptions, given limited existing public knowledge about neonicotinoids. Consumer preferences are malleable by information intervention as characterized in the information-deficit model (Gross, 1994). Under the influence of issue-specific information (i.e. the impact of neonicotinoids on pollinator health), participants (knowledgeable participants particularly) showed greater support and preference for products with labels disclosing the absence of neonicotinoids. Were these effects to be generalized to the broader agrifood context, they have practical relevance for policy makers in shaping socially optimal policies related to the use of neonicotinoids in agriculture. Even though the use of neonicotinoids in the ornamental industry is non-negligible, they are predominantly used in agricultural field crop production. With the significance of both information treatments on influencing consumers' choices toward neonicotinoid-free products, government agencies may consider informational intervention utilizing unbiased information to emphasize pollinator conservation efforts. Educational programs emphasizing unbiased information are also helpful in fostering a healthy public opinion about neonicotinoids. Leveraging policy restrictions such as a ban or mandatory labeling often results in significant market frictions. Most recent studies have revealed that the EU's ban on neonicotinoids has caused a yield decrease (Dewar, 2016; Noleppa, 2017) and an increase in production costs (Noleppa, 2017). Banning neonicotinoids has also forced farmers to use alternative means of pest control which may have unintended consequences such as pest resistance to common pesticide controls (Bass and Field, 2018). On the other hand, informational intervention has the potential to shift consumer demand for more environmentally friendly products. 
The present study has also provided insights into the asymmetric impact of information on different labeling practices. Additional information about neonicotinoids tends to have a larger impact on consumer preferences for labels disclosing the absence of neonicotinoids than labels disclosing the presence of neonicotinoids. Additional information has more influence on less knowledgeable participants' preference for phrases disclosing the presence of neonicotinoids. This has practical implications for policy makers and green industry stakeholders when considering label format and information framing.

Consistent with prior research on preferences for GM labeling (e.g. Lusk et al., 2004; Poortinga and Pidgeon, 2004), we also found that respondents' initial attitudes and knowledge toward neonicotinoids play an important role in how individuals respond to newly provided information and thus their choice decisions. Distinct differences were found between the knowledgeable and unknowledgeable groups. However, people with strong preconceptions may still change their existing attitudes after a persuasive and unbiased information is provided. This finding has important implications for policy makers to effectively foster the public's perceptions. It suggests that less knowledgeable consumers can be encouraged to select more environmentally friendly products through the use of educational promotions that emphasize important and relevant information. The take-home message is that consumers value the absence of neonicotinoids and are likely to change their product choice based on received information. From the managerial perspective, policy makers may consider educational programs emphasizing unbiased information to foster a healthy public opinion about neonicotinoids. While mandatory neonicotinoid labeling is still under investigation by the U.S. federal government, major ornamental horticulture industry stakeholders may want to consider utilizing the first-mover advantage by participating in voluntary labeling strategies communicating the absence of neonicotinoids to capture this positive consumer surplus.

Finally, due to the upward bias in a hypothetical choice-based experiment setting, our WTP estimates are presumably higher than consumers' true WTP. Particularly, WTP estimates for the knowledgeable group under the negative information treatment could be amplified due to the combined effects of upward hypothetical bias (in a hypothetical setting), confirmatory bias (from the knowledgeable group), a negativity bias (from the negative information treatment). Although correction of all these types of biases are out of the scope of this research, it would be worthwhile taking this into consideration in future research when estimating the effect of different labeling practices (i.e. mandatory vs voluntary labeling) on real demand for neonicotinoidfree products.

\section{Supplementary material}

Supplementary material can be found online at https://doi.org/10.22434/IFAMR2020.0158

Table S1. Discrete choice experiment attributes and attribute levels.

Table S2. Estimates from mixed logit models for annual plants (4-inch container).

Table S3. Estimates from mixed logit models for perennial plants (1-gallon container).

Figure S1. Sample choice set from the online survey.

\section{Acknowledgements}

The authors thank Dr. Xianwei Meng for his helpful discussion and comments throughout the development and preparation of this manuscript.

\section{Funding}

This research was funded by USDA Specialty Crop Research Initiative Competitive Grant No. 2016-51181235399. 


\section{Conflicts of interest}

The authors declare no conflict of interest.

\section{References}

Bass, C. and L.M. Field. 2018. Neonicotinoids. Current Biology 28: R761-R783.

Bauer, M.W. 2005. Public perceptions and mass media in the biotechnology controversy. International Journal of Public Opinion Research 17(1): 5-22. https://doi.org/10.1093/ijpor/edh054

Baumeister, R.F., E. Bratslavsky, C. Finkenauer and K.D. Vohs. 2001. Bad is stronger than good. Review of General Psychology 5(4): 323-370.

Bethke, J.A. and R.A. Cloyd. 2009. Pesticide use in ornamental production: what are the benefits? Pest Management Science 65: 345-350.

Blacquiere, T., G. Smagghe, C.A.M. Van Gestel and V. Mommaerts. 2012. Neonicotinoids in bees: a review on concentrations, side-effects and risk assessment. Ecotoxicology 21(4): 973-992.

Bougherara, D. and P. Combris. 2009. Eco-labelled food products: what are consumers paying for? European Review of Agricultural Economics 36(3): 321-341.

Campbell, B.L. and W. Steele. 2020. Impact of information type and source on pollinator-friendly plant purchasing. HortTechnology 30(1): 122-128.

Caswell, J.A. 2000. An evaluation of risk analysis as applied to agricultural biotechnology. Agribusiness 16(1): 115-123.

Cook, G., P.T. Robbins and E. Pieri. 2006. Words of mass destruction: British newspaper coverage of the genetically modified food debate, expert and non-expert reactions. Public Understanding of Science 15(1): 5-29.

Dewar, A.M. 2016. The adverse impact of the neonicotinoid seed treatment ban on crop protection in oilseed rape in the United Kingdom. Pest Management Science 73(7): 1305-1309.

Dillman, D.A., J.D. Smyth and L.M. Christian. 2011. Internet, mail, and mixed-mode surveys: the tailored design method. Wiley, Hoboken, NJ, USA.

Douglas, M.R. and J.F. Tooker. 2015. Large-scale deployment of seed treatments has driven rapid increase in use of neonicotinoid insecticides and preemptive pest management in U.S. field crops. Environmental Science \& Technology 49(8): 5088-5097.

Douglas, M.R. and J.F. Tooker. 2016. Meta-analysis reveals that neonicotinoid seed treatments and pyrethroids have similar negative effects on abundance of arthropod natural enemies. PeerJ Plant Biology Section 4: e2776. https://doi.org/10.7717/peerj.2776

Fairbrother, A., J. Purdy, T. Anderson and R. Fell. 2014. Risks of neonicotinoid insecticides to honeybees. Environmental Toxicology and Chemistry 33(4): 719-731.

Fennell, G., G.M. Allenby, S. Yang and Y. Edwards. 2003. The effectiveness of demographic and psychographic variables for explaining brand and product category use. Quantitative Marketing and Economics 1: 223-244.

Fernbach, P.M., N. Light, S.E. Scott, Y. Inbar and P. Rozin. 2019. Extreme opponents of genetically modified foods know the least but think they know the most. Nature Human Behaviour 3(3): 251-256. https://doi.org/10.1038/s41562-018-0520-3

Fox, J.A., D.J. Hayes and J. Shogren. 2002. Consumer preferences for food irradiation: how favorable and unfavorable descriptions affect preferences for irradiated pork in experimental auctions. Journal of Risk and Uncertainty 24(1): 75-95.

Frewer, L.J., C. Howard, D. Hedderley and E. Shepherd, 1999. Reactions to information about genetic engineering: impact of source characteristics, perceived personal relevance and persuasiveness. Public Understanding of Science 8: 33-50.

Frewer, L.J., S. Miles and R. Marsh 2002. The media and genetically modified foods: evidence in support of social amplification of risk. Risk Analysis 22(4): 701-711.

Goulson, D. 2013. An overview of the environmental risks posed by neonicotinoid insecticides. Journal of Applied Ecology 50: 977-987. 
Goulson, D., E. Nicholls, C. Botias and E.L. Rotheray. 2015. Bee declines driven by combined stress from parasites, pesticides, and lack of flowers. Science 347: 1435-1443. https://doi.org/10.1126/ science. 1255957

Griffis, S.E., T.J. Goldsby and M. Cooper. 2003. Web-based and mail surveys: a comparison of response, data, and cost. Journal of Business Logistics 24(2): 237-258.

Gross, A.G. 1994. The roles of rhetoric in the public understanding of Science. Public Understanding of Science 3: 3-23.

$\mathrm{Hu}, \mathrm{W} .2006$. Comparing consumers' preferences and willingness to pay for non-GM oil using a contingent valuation approach. Empirical Economics 31: 143-150.

Hu, W., M.M. Veeman and W.L. Adamowicz. 2005. Labeling genetically modified food: heterogeneous consumer preferences and the value of information. Canadian Journal of Agricultural Economics 53: 83-102.

Jeschke, P. and R. Nauen. 2008. Neonicotinoids - from zero to hero in insecticide chemistry. Pest Management Science 64(11): 1084-1098.

Jeschke, P., R. Nauen, M. Schindler and A. Elbert. 2011. Overview of the status and global strategy for neonicotinoids. Journal of Agricultural and Food Chemistry 59(7): 2897-2908.

Kuhfeld, W.F. 2010. Marketing research methods in SAS: experimental design, choice, conjoint, and graphical techniques. SAS Institute Inc., Cary, NC, USA. Available at: http://support.sas.com/techsup/technote/ mr2010.pdf

Li, J., M.I. Gómez, B.J. Rickard and M. Skinner. 2013. Factors influencing adoption of integrated pest management in northeast greenhouse and nursery production. Agricultural and Resource Economics Review 42(2): 310-324.

Li, T. and J.J. McCluskey. 2017. Consumer preferences for second-generation bioethanol. Energy Economics 61: $1-7$.

Li, T., J.R. Fooks and K.D. Messer and P.J. Ferraro. 2019. A field experiment to estimate the effects of anchoring and framing on residents' willingness to purchase water runoff management technologies. Resource and Energy Economics 63: 101107. https://doi.org/10.1016/j.reseneeco.2019.07.001

Liaukonyte, J., N.A. Streletskaya, H.M. Kaiser and B.J. Rickard. 2013. Consumer response to 'contains' and 'free of' labeling: evidence from lab experiments. Applied Economic Perspectives and Policy 35(3): 476-507.

Lundin, O., M. Rundlöf, H.G. Smith, I. Fries and R. Bommarco. 2015. Neonicotinoid insecticides and their impacts on bees: a systematic review of research approaches and identification of knowledge gaps. PLoS ONE 10(8): e0136928.

Lusk, J.L. and D. Hudson. 2004. Willingness-to-pay estimates and their relevance to agribusiness decision making. Review of Agricultural Economics 26(2): 152-169.

Lusk, J.L., L.O. House, C. Valli, S.R. Jaeger, M. Moore, J.L. Morrow and W.B. Trail. 2004. Effects of information about benefits of biotechnology on consumer acceptance of genetically modified food: evidence form experimental auctions in the United States, England, and Frances. European Review of Agricultural Economics 31(2): 179-204.

Marks, L.A., N. Kalaitzandonakes, L. Wilkins and L. Zakharova. 2007. Mass media framing of biotechnology news. Public Understanding of Science 16(2): 183-203.

McCluskey, J.J. and J.F.M. Swinnen. 2004. Political economy of the media and consumer perceptions of biotechnology. American Journal of Agricultural Economics 86(5): 1230-1237.

McCluskey, J.J., N. Kalaitzandonakes and J. Swinnen. 2016. Media coverage, public perceptions, and consumer behavior: insights from new food technologies. Annual Review of Resource Economics 8: 467-486.

McFadden, B.R. and J.L. Lusk. 2015. Cognitive biases in the assimilation of scientific information on global warming and genetically modified food. Food Policy 54: 35-43.

McFadden, B.R. and J.L. Lusk. 2018. Effects of the national bioengineered food disclosure standard: willingness to pay for labels that communicate the presence or absence of genetic modification. Applied Economic Perspectives and Policy 40(2): 259-275.

McFadden, D. and K. Train. 2000. Mixed MNL models of discrete response. Journal of Applied Economics 15: 447-470. 
Meise, J.N., T. Rudolph, P. Kenning and D.M. Phillips. 2014. Feed them facts: value perceptions and consumer use of sustainability-related product information. Journal of Retailing and Consumer Services 21(4): 510-519.

Messer, K.D., M. Costanigro and H.M. Kaiser. 2017. Labeling food processes: the good, the bad and the ugly. Applied Economics Perspectives and Policy 39(3): 407-427.

Michaud, C., D. Llerena and I. Joly. 2013. Willingness to pay for environmental attributes of non-food agricultural products: a real choice experiment European Review of Agricultural Economics 40(2): 313-329.

National Gardening Association. 2019. National Gardening Survey 2019 edition - a comprehensive study of consumer gardening practices, trends \& product sales. NGA's Research Division, Jacksonville, TX, USA.

Nauen, R., P. Jeschke and L. Copping. 2008. In focus: neonicotinoid insecticides. Pest Management Science 64: 1081.

Noleppa, S. 2017. Banning neonicotinoids in the European Union: an ex-post assessment of economic and environmental costs. HFFA Research Paper 01/2017, HFFA GmbH, Berlin, Germany.

Peeters, G. and J. Czapinski. 1990. Positive-negative asymmetry in evaluations: the distinction between affective and informational negativity effects. European Review of Social Psychology 1(1): 33-60.

Pilling, E., P. Campbell, M. Coulson, N. Ruddle and I. Tornier. 2013. A four-year field program investigating long-term effects of repeated exposure of honeybee colonies to flowering crops treated with thiamethoxam. PLoS ONE 8(10): e77193.

Pisa, L.W., V. Amaral-Rogers, L.P. Belzunces, J.M. Bonmatin, C.A. Downs, D. Goulson, D.P. Kreutzweiser, C. Krupke, M. Liess, M. McField, C.A. Morrissey, D.A. Noome, J. Settele, N. Simon-Delso, J.D. Stark, J.P. Van der Sluijs, H. Van Dyck and M. Wiemers. 2015. Effects of neonicotinoids and fipronil on non-target invertebrates. Environmental Science and Pollution Research 22(1): 68-102. https://doi.org/10.1007/s11356-014-3471-x

Poortinga, W. and N.F. Pidgeon. 2004.Trust, the asymmetry principle, and the role of prior beliefs. Risk Analysis 24(6): 1474-1486.

Revelt, D. and K. Train. 1998. Mixed logit with repeated choices: households' choices of appliance efficiency level. The Review of Economics and Statistics 80(4): 647-657.

Rihn, A. and H. Khachatryan. 2016. Does consumer awareness of neonicotinoid insecticides influence their preferences for plants? HortScience 51: 388-393.

Rousseau, S. and L. Vranken. 2013. Green market expansion by reducing information asymmetries: evidence for labeled organic food products. Food Policy 40: 31-43.

Sanchez-Bayo, F. and K. Goka. 2014. Pesticide residues and bees - a risk assessment. PLoS ONE 9(4): e94482. https://doi.org/10.1371/journal.pone.0094482

Siegrist, M. and G. Cvetkovich. 2001. Better negative than positive? Evidence of a bias for negative information about possible health dangers. Risk Analysis 21(1): 199-206.

Sörqvist, P., A. Haga, L. Langeborg, M. Holmgren, M. Wallinder, A. Nöstl, P.B. Seager and J.E. Marsh. 2015. The green halo: mechanisms and limits of the eco-label effect. Food Quality \& Preference 43: 1-9.

Streletskaya, N.A., J. Liaukonyte and H.M. Kaiser. 2019. Absence labels: how does information about production practices impact consumer demand? PLoS ONE 14(6): e0217934. https://doi.org/10.1371/ journal.pone.0217934

Swait, J. and W. Adamowicz. 2001. The influence of task complexity on consumer choice: a latent lass model of decision strategy switching. Journal of Consumer Research 28(1): 135-148.

Tooker, J.F., M.R. Douglas and C.H. Krupke. 2017. Neonicotinoid seed treatments: limitations and compatibility with integrated pest management. Agricultural \& Environmental Letters 2: 1-5.

Train, K. 2009. Mixed logit. Discrete choice methods with simulation. Cambridge University Press, New York, NY, USA, pp. 134-150.

U.S. Department of Agriculture National Agricultural Statistics Service (USDA NASS). 2014. 2014 census of horticultural specialties. USDA, Washington, DC, USA.

U.S. Census Bureau. 2019. American community survey. U.S. Census Bureau, Washington, DC, USA. Available at: https://data.census.gov/ 
Van der Sluijs, J.P., N. Simon-Delso, D. Goulson, L. Maxim, J.M. Bonmatin and L.P. Belzunces. 2013. Neonicotinoids, bee disorders and the sustainability of pollinator services. Current Opinion in Environmental Sustainability 5(3-4): 293-305.

Van Loo, E.J., V. Caputo, R.M. Nayga Jr., H. Seo, B. Zhang and W. Verbeke. 2015. Sustainability labels on coffee: consumer preferences, willingness-to-pay and visual attention to attributes. Ecological Economics 118: 215-225.

Vilella-Vila, M. and J. Costa-Font. 2008. Press media reporting effects on risk perceptions and attitudes towards genetically modified (GM) foods. The Journal of Socio-Economics 37(5): 2095-2106.

Wei, X., H. Khachatryan and R. Alicia. 2020. Consumer preferences for labels disclosing the use of neonicotinoid pesticides: evidence from experimental auctions. Journal of Agricultural and Resource Economics 45(3): 496-517.

Weinberger, M.G. and W.R. Dillon. 1980. The effects of unfavorable product rating information. Advances in Consumer Research 7(1): 528-532.

Wollaeger, H.M., K.L. Getter and B.K. Behe. 2015. Consumer preferences for traditional, neonicotinoidfree, bee-friendly, or biological control pest management practices on floriculture crops. HortScience 50: 721-732. 
